\title{
Thermal properties of citronellyl diesters
}

\author{
Marta Worzakowska
}

Received: 6 December 2013/Accepted: 11 June 2014/Published online: 8 July 2014

(c) The Author(s) 2014. This article is published with open access at Springerlink.com

\begin{abstract}
Thermal properties of linear citronellyl diesters were studied by TG/DSC/FTIR/QMS-coupled method in inert and oxidative atmospheres. The diesters decompose in one main step in inert atmosphere. As main pyrolysis products, the formation of mainly monoterpene hydrocarbons, acid anhydrides, monoacids, cyclic ketones, aldehyde fragments, carbon dioxide, and water was observed. It was indicated on the ester and $O$-citronellyl bonds cleavage, partial decarboxylation, and elimination of water from formed dicarboxylic acids during their pyrolysis. The decomposition in air runs in two steps. The first step was connected with the creation of monoterpene hydrocarbons, monoacids, cyclic ketones, aldehydes, carbon dioxide, carbon monoxide, and water. In the second step of decomposition, mainly carbon dioxide and water were produced. It was testified to ester and $O$-citronellyl bonds cleavage, partial oxygenation, and decarboxylation process of the primary formed decomposition products.
\end{abstract}

Keywords Citronellyl diesters · TG/FTIR/QMS-coupled method . Thermal degradation

\section{Introduction}

Citronellol (3,7-dimethyl-6-octen-1-ol) is a natural, acyclic, primary terpene alcohol with one carbon-carbon double bond in the structure. Citronellol is a colorless liquid with an agreeable, sweet roselike odor. It is found in

M. Worzakowska ( $\square)$

Department of Polymer Chemistry, Faculty of Chemistry, Maria

Curie-Skłodowska University, Gliniana 33 Street,

20-614 Lublin, Poland

e-mail: marta.worzakowska@ poczta.umcs.lublin.pl many natural products like oils from Boronia citriodora, Eucalyptus citriodora, Cymbopogon nardus, and Pelargonium geraniums. It is one of the most popular and widely used fragrance materials and as insect repellents and as a mite attractant. It is starting material for the production of citronellyl esters, hydroxydihydrocitronellol and as an intermediate in the preparation of hydroxydihydrocitronellal [1-5].

Esters of short chain fatty acids and primary, terpene alcohols e.g., geraniol, nerol, and citronellol are commonly known and applied in the industry as a flavor and fragrance compounds. Citronellyl esters e.g., citronellyl formate, acetate, propionate, isobutyrate ,or tiglate are used in relatively large amounts in the food, beverages, cosmetics, and pharmaceutical industries [6-8]. In addition, esters of dicarboxylic acids or acid anhydrides and terpene alcohols are one of the slowly hydrolyzable groups of diesters which are commercially added to many products as pro-fragrances components. Among them, the most popular diesters are the esterification products of succinic anhydride and geraniol or nerol $[9,10]$. Those esters are obtained by traditional methods like esterification process without or with the use of strong acid catalyst or amine catalyzed [11, 12].

The previous papers are focused on the synthesis and thermal properties of geranyl and neryl diesters. Recently, the proposal of the use of tin catalyst for esterification process of primary, terpene alcohols: geraniol and nerol and linear, aliphatic chain acid anhydrides or dicarboxylic acids was presented. It allowed preparing the final products with high yield and purity in mild synthesis conditions [13, 14]. The current paper focuses on the thermal properties of non-described in the literature, flavor citronellyl diesters which were prepared during the same reaction conditions as previously described $[13,14]$. The objective of this study is to better understand the relationship between 
Table 1 The final conversion of citronellol and carboxylic groups

\begin{tabular}{lcll}
\hline Diester & $\begin{array}{l}\text { Reaction } \\
\text { time/h }\end{array}$ & $\begin{array}{l}\text { Conversion of } \\
\text { citronellol/\% }\end{array}$ & $\begin{array}{l}\text { Conversion of } \\
\text { carboxylic } \\
\text { groups/\% }\end{array}$ \\
\hline Dicitronellyl succinate & 4 & 98.5 & 97.9 \\
Dicitronellyl glutarate & 6 & 98.4 & 97.5 \\
Dicitronellyl adipinate & 8 & 98.5 & 97.8 \\
Dicitronellyl sebacinate & 10 & 98.3 & 97.2
\end{tabular}

${ }^{\mathrm{a}}$ Final conversion of citronellol estimated based on ${ }^{1} \mathrm{H}$ NMR spectra

${ }^{b}$ Final conversion of carboxylic groups based on residual acid content

the structure, thermal properties, and degradation mechanism of diesters formed with the use of primary, terpene alcohols, which can find potential applications as perfumes (deodorants) for many products manufactured in high temperature processing e.g., for polymers, plastics and their commercial products like toys, artificial flowers, bric-a-bracs ,or other commemorative products, etc.

\section{Experimental}

\section{Materials}

Citronellol (95\%) and glutaric anhydride (95\%) were from Fluka. Succinic anhydride (99\%), adipic acid (99\%)<smiles>CC(C)=CCCC(C)CCCC(=O)OCCC(C)CCC=C(C)C</smiles>

Fig. 1 The molecular formula of citronellyl diesters, where $n=2,3$, 4 , or 8

and sebacic acid (98\%) were from Merck. Butylstannoic acid (catalyst) was delivered by Arkema Inc., USA. The reagents were used as received.

Synthesis

Citronellyl diesters were obtained in direct catalyzed esterification process of citronellol and suitable acidic reagent. The reagents were used at the ratio of 2 mol of citronellol and $1 \mathrm{~mol}$ of acidic component. In a typical procedure, citronellol (16.45 g) and suitable acidic reagents such as succinic anhydride $(5.05 \mathrm{~g})$, or glutaric anhydride $(6.00 \mathrm{~g})$, or adipic acid $(7.38 \mathrm{~g})$, or sebacic acid $(10.32 \mathrm{~g})$, and a catalyst $(0.05 \mathrm{mass} \%)$ were weighted into three-necked round-bottomed $50 \mathrm{~mL}$ flask. The glass flask was equipped with mechanical strirrer, thermometer, and distillation condenser connected to the reduced pressure. The reaction mixture was heated up to $130{ }^{\circ} \mathrm{C}$ and stirred

Table 2 Physical properties of citronellyl diesters

\begin{tabular}{|c|c|c|c|c|}
\hline Properties & Dicitronellyl succinate & Dicitronellyl glutarate & Dicitronellyl adipinate & Dicitronellyl sebacinate \\
\hline Viscosity/mPa s & 11.5 & 14.5 & 24.9 & 32.7 \\
\hline Density/g cm $\mathrm{cm}^{-3}$ & 0.9630 & 0.9750 & 0.9780 & 0.9860 \\
\hline Refractive index & 1.4750 & 1.4780 & 1.4810 & 1.4820 \\
\hline
\end{tabular}

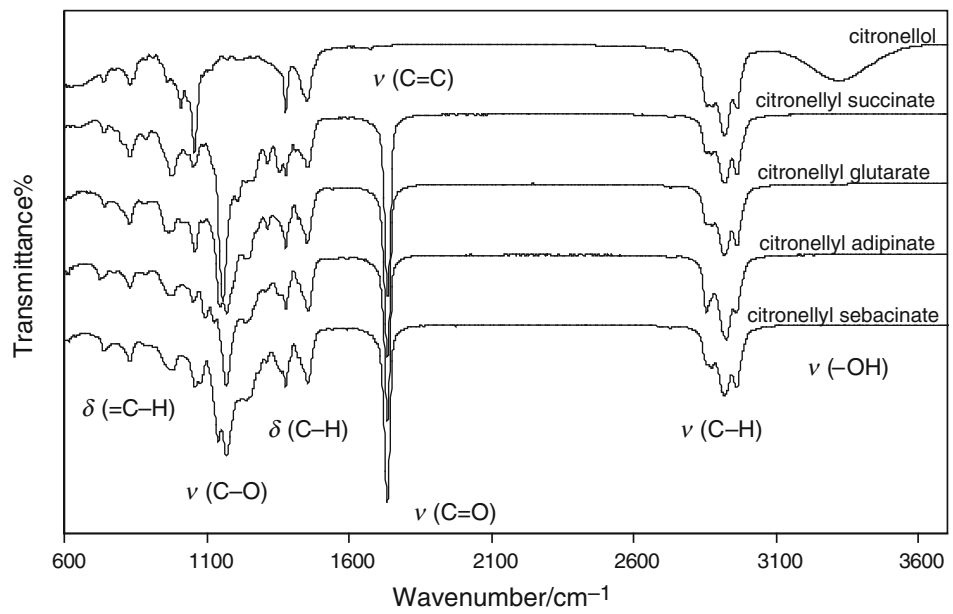

Fig. 2 ATR-FTIR spectra of citronellol, citronellyl succinate, citronellyl glutarate, citronellyl adipinate, and citronellyl sebacinate 
<smiles>CC(C)=CCCC(C)CCOC(=O)CCCCCC(=O)OCCCCCC(C)C</smiles>

dicitronellyl succinate
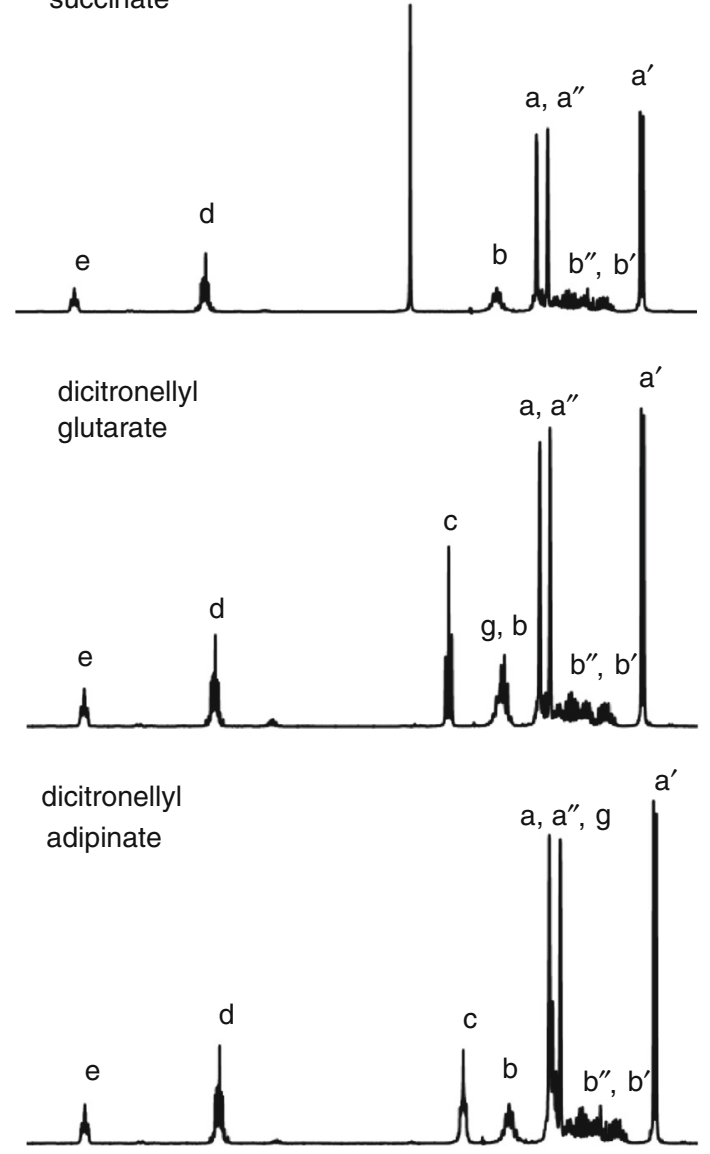

dicitronellyl sebacinate

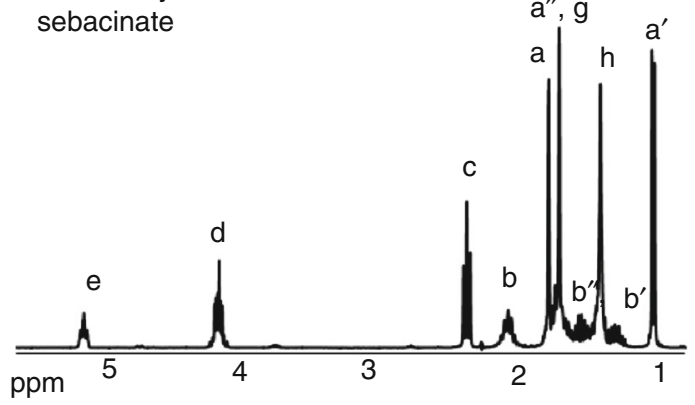

Fig. $3{ }^{1} \mathrm{H}$ NMR spectra of citronellyl diesters: citronellyl succinate, citronellyl glutarate, citronellyl adipinate, and citronellyl sebacinate<smiles>CC(C)=CCCC(C)CCOC(=O)CCCCCC(C)(C)CCCC(C)C</smiles>

dicitronelly

$a, a^{\prime}, a^{\prime \prime}, b$,

succinate e $\quad b^{\prime}, b^{\prime \prime}, c$
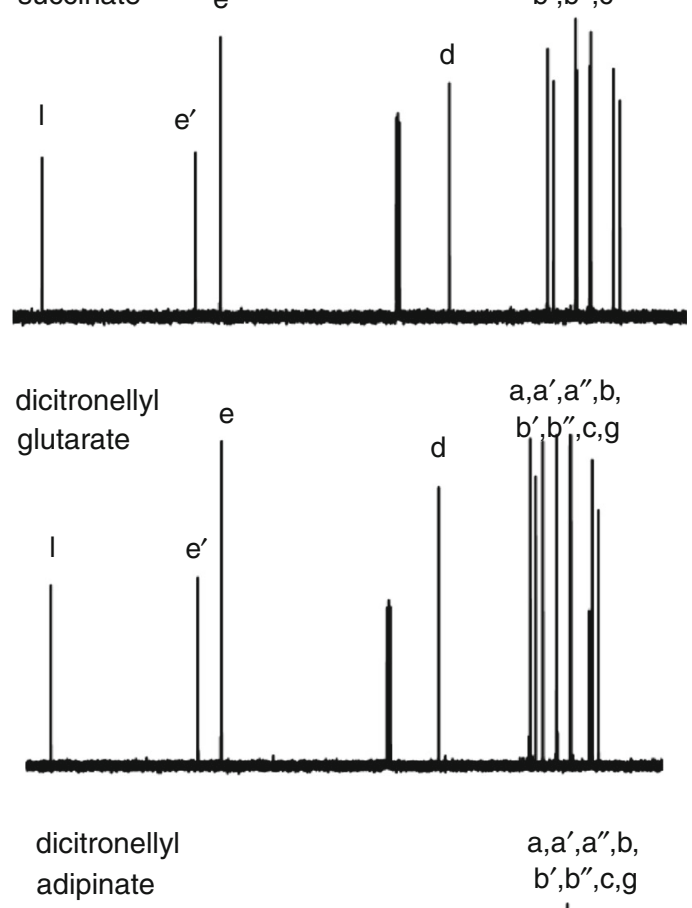

adipinate

, b", c,g
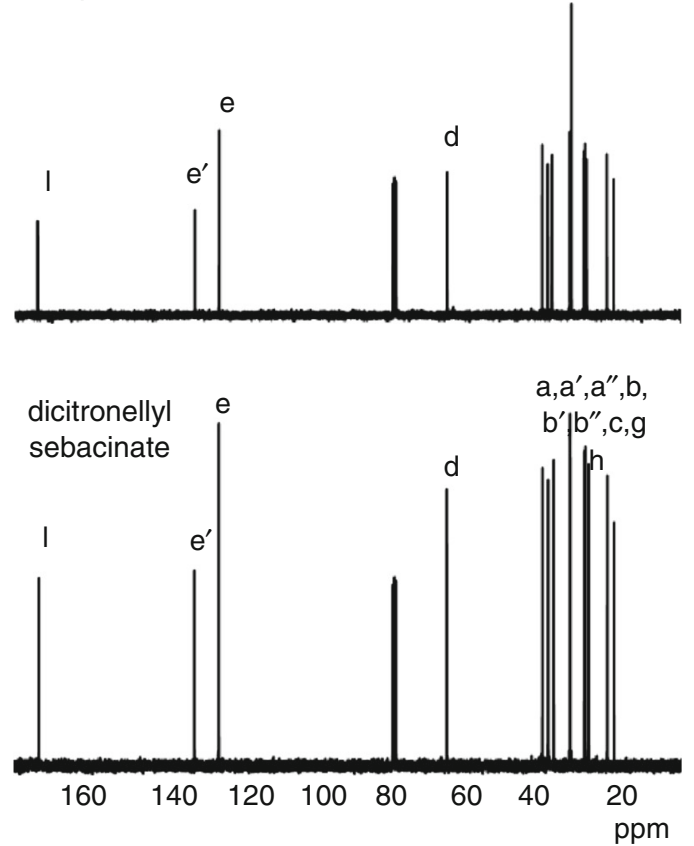

Fig. $4{ }^{13} \mathrm{C}$ NMR spectra of citronellyl diesters: citronellyl succinate, citronellyl glutarate, citronellyl adipinate, and citronellyl sebacinate 
Table 3 TG-DTG data of citronellyl diesters in inert atmosphere

\begin{tabular}{lllllllll}
\hline Diester & $T_{5} \% /{ }^{\circ} \mathrm{C}$ & $T_{10 \%} /{ }^{\circ} \mathrm{C}$ & $T_{20} \% /{ }^{\circ} \mathrm{C}$ & $T_{50 \%} /{ }^{\circ} \mathrm{C}$ & $T_{\max 1} /{ }^{\circ} \mathrm{C}$ & $T_{\text {onset DSC }} /{ }^{\circ} \mathrm{C}$ & $T_{\max 1 \mathrm{DSC}} /{ }^{\circ} \mathrm{C}$ & $T_{\text {end DSC }} /{ }^{\circ} \mathrm{C}$ \\
\hline Dicitronellyl succinate & 210 & 232 & 260 & 282 & 294 & 240 & 290 & 310 \\
Dicitronellyl glutarate & 220 & 245 & 272 & 294 & 301 & 250 & 300 & 320 \\
Dicitronellyl adipinate & 230 & 260 & 285 & 310 & 320 & 260 & 320 & 350 \\
Dicitronellyl sebacinate & 250 & 273 & 293 & 321 & 336 & 270 & 340 & 360 \\
\hline
\end{tabular}

under reduced pressure (200 mbar) in a thermostatic oil bath $[13,14]$. The progress of the reaction was monitored by the determination of the residual acid number and by estimation of Proton nuclear magnetic resonance $\left({ }^{1} \mathrm{H}\right.$ NMR) spectra [15]. In those studies, the integration values of methylene protons of citronellol $(\delta=3.6 \mathrm{ppm})$ and methylene protons of citronellyl diesters $(\delta=$ $4.10 \mathrm{ppm}$ ) were chosen for the calculation of percentage conversion of primary, terpene alcohol. The final conversion of citronellol and acidic reagent is placed in Table 1. The product was analyzed by FTIR, ${ }^{1} \mathrm{H}$ NMR, and ${ }^{13} \mathrm{C}$ NMR spectra. The physical properties of diesters: density, viscosity , and refractive index are presented in Table 2.

\section{Methods}

${ }^{1} \mathrm{H}$ NMR spectra were obtained using an NMR BruckerAvance $300 \mathrm{MSL}$ (Germany) spectrometer at $300 \mathrm{MHz}$ with deuterated chloroform $\left(\mathrm{CDCl}_{3}\right)$ as the solvent. ${ }^{1} \mathrm{H}$ NMR chemical shifts in parts per million (ppm) were reported downfield from $0.00 \mathrm{ppm}$ using tetramethylsilane as an internal reference.

Attenuated total reflection (ATR) were recorded using infrared Fourier transform spectroscopy on spectrometer Brucker TENSOR 27, equipped with diamond crystal (Germany). The spectra were recorded in the spectral range of $600-4000 \mathrm{~cm}^{-1}$ with 16 scans per spectrum at a resolution of $4 \mathrm{~cm}^{-1}$.

${ }^{13}$ CNMR spectra were recorded on a Brucker 300MSL instrument (Germany). Chemical shifts were referred to chloroform serving as an internal standard.

Viscosity was measured by means of rotating spindle rheometer at $25^{\circ} \mathrm{C}$, Brookfield, model DV-III (Germany).

Density was evaluated using a glass pycnometer with capillary fuse Gay/Lussac $(25 \mathrm{~mL})$ at $23{ }^{\circ} \mathrm{C}$.

Refractive index was determined by refractometer Carl Zeis Jena at $23{ }^{\circ} \mathrm{C}$.

Acid number $\left(\mathrm{mgKOH} \mathrm{g}^{-1}\right)$ was evaluated by titration of the sample against potassium hydroxide using phenolphthalein as an indicator and acetone as a solvent.

Thermal analysis was carried out on a STA 449 Jupiter F1, Netzsch (Germany). The samples were heated from 40 to $700{ }^{\circ} \mathrm{C}$ with a heating rate of $10{ }^{\circ} \mathrm{C} \mathrm{min}-1$ under a dynamic atmosphere of helium $\left(40 \mathrm{~mL} \mathrm{~min}{ }^{-1}\right)$ or synthetic
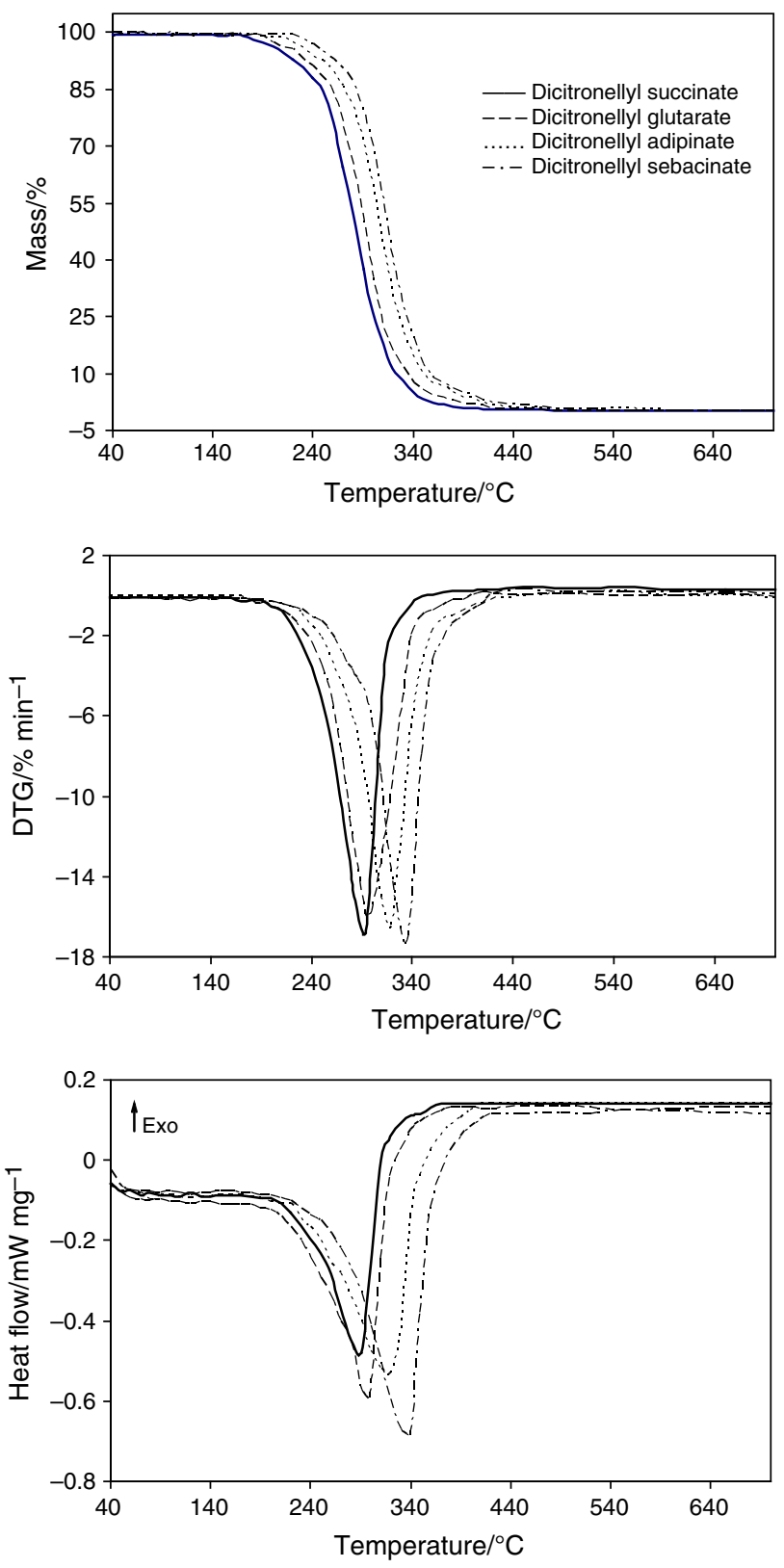

Fig. 5 TG, DTG, and DSC curves of citronellyl diesters in helium

air $\left(40 \mathrm{~mL} \mathrm{~min}^{-1}\right)$. The sensor thermocouple type $\mathrm{S} \mathrm{TG}-$ DSC and empty $\mathrm{Al}_{2} \mathrm{O}_{3}$ crucible as reference were used. The gaseous products emitted during decomposition of diesters were analyzed by FT IR spectrometer Brucker (Germany) and by QMS 403C Aëolos (Germany) coupling 

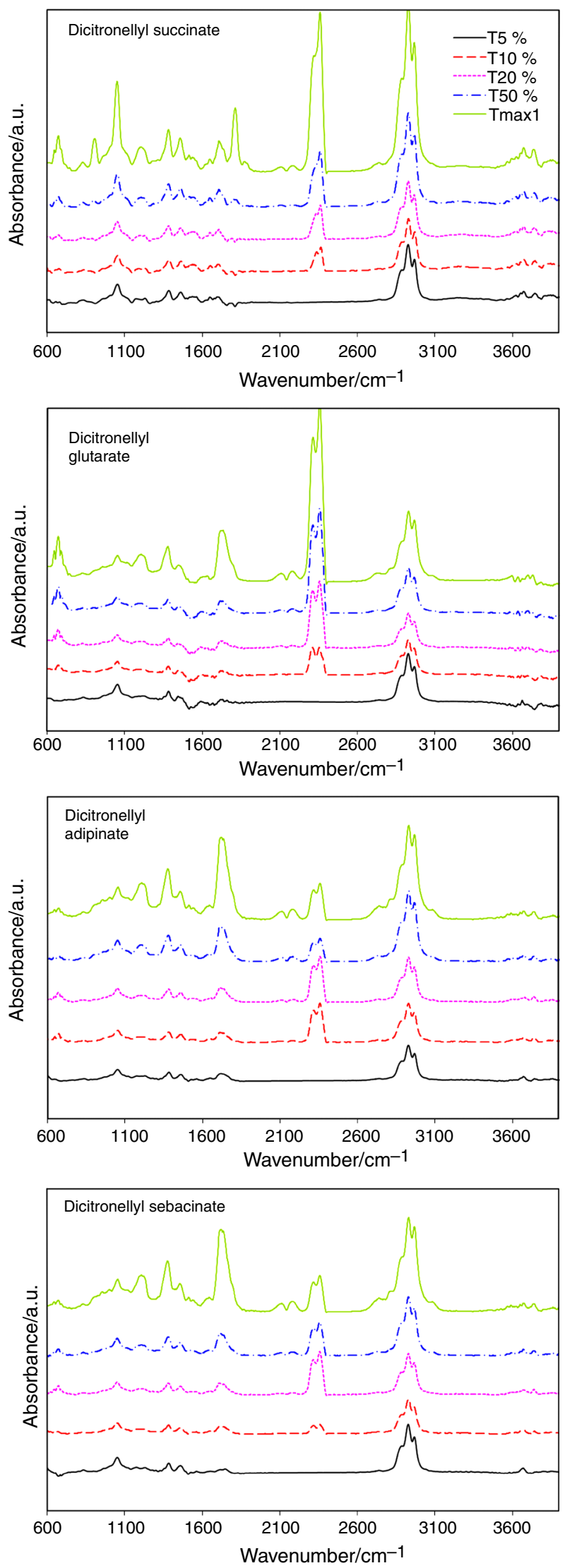

Fig. 6 FTIR spectra of decomposition products emitted in helium

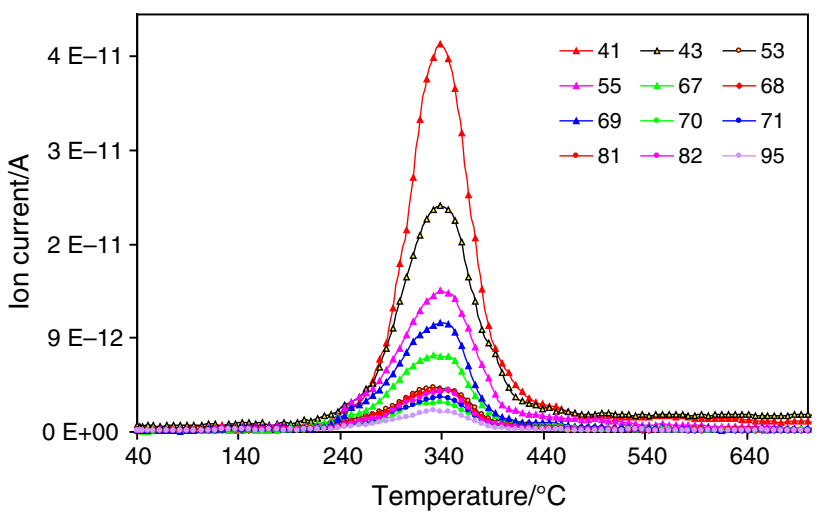

Fig. 7 The example QMS spectra of ions $(\mathrm{m} / \mathrm{z})$ for hydrocarbons which are formed during heating of diesters in helium

on-line to STA instrument. The QMS data were gathered in the range from 10 to $150 \mathrm{amu}$. The FTIR spectra were recorded in the spectral range of $600-4000 \mathrm{~cm}^{-1}$ with 16 scans per spectrum at a resolution of $4 \mathrm{~cm}^{-1}$.

\section{Results and discussion}

The theoretical molecular formula of obtained diesters is presented in Fig. 1. The use of butylstannoic acid as a catalyst allows obtaining final product with high yield and purity. The conversion of terpene alcohol was higher than $98 \%$, the conversion of carboxylic groups was higher than $97 \%$, respectively (Table 1 ). In addition, citronellyl diesters were prepared in shorter reaction time compared to those previously studied [13, 14]. It indicated on higher reactivity of terpene alcohol having one carbon-carbon double bond in the structure during catalyzed esterification process than terpene alcohols with two carbon-carbon double bonds in their structure.

The prepared diesters derivatives of citronellol are flavor oils with intensive, citrus-geranium odor. The esters are easily soluble in organic solvents but insoluble in water. Their physical properties are presented in Table 2. The obtained citronellyl diesters were characterized by lower density, viscosity, and refractive index than previously studied [13, 14].

Their structure was confirmed by performing FTIR and NMR spectra. The FTIR spectra of citronellol and obtained citronellyl diesters are placed in Fig. 2. It is clearly visible the loss of the bands at 3315,1056 , and $1109 \mathrm{~cm}^{-1}$ responsible for the stretching vibrations of hydroxyl group $(\mathrm{v}-\mathrm{OH})$ and stretching vibrations of $\mathrm{C}-\mathrm{O}$ groups in alcohols $\left(\mathrm{v}-\mathrm{CH}_{2} \mathrm{OH}\right)$. The appearance of new absorption bands at 1734, 1052, 1125 , and $1313 \mathrm{~cm}^{-1}$ which corresponds to the stretching vibrations of carbonyl groups $(\mathrm{v}-\mathrm{C}=\mathrm{O})$ and $\mathrm{C}-\mathrm{O}$ bonds in esters of aliphatic acids $(\mathrm{v}-\mathrm{C}-\mathrm{O})$ is brightly seen. Also, the presence of the following signals connected with the stretching vibrations 

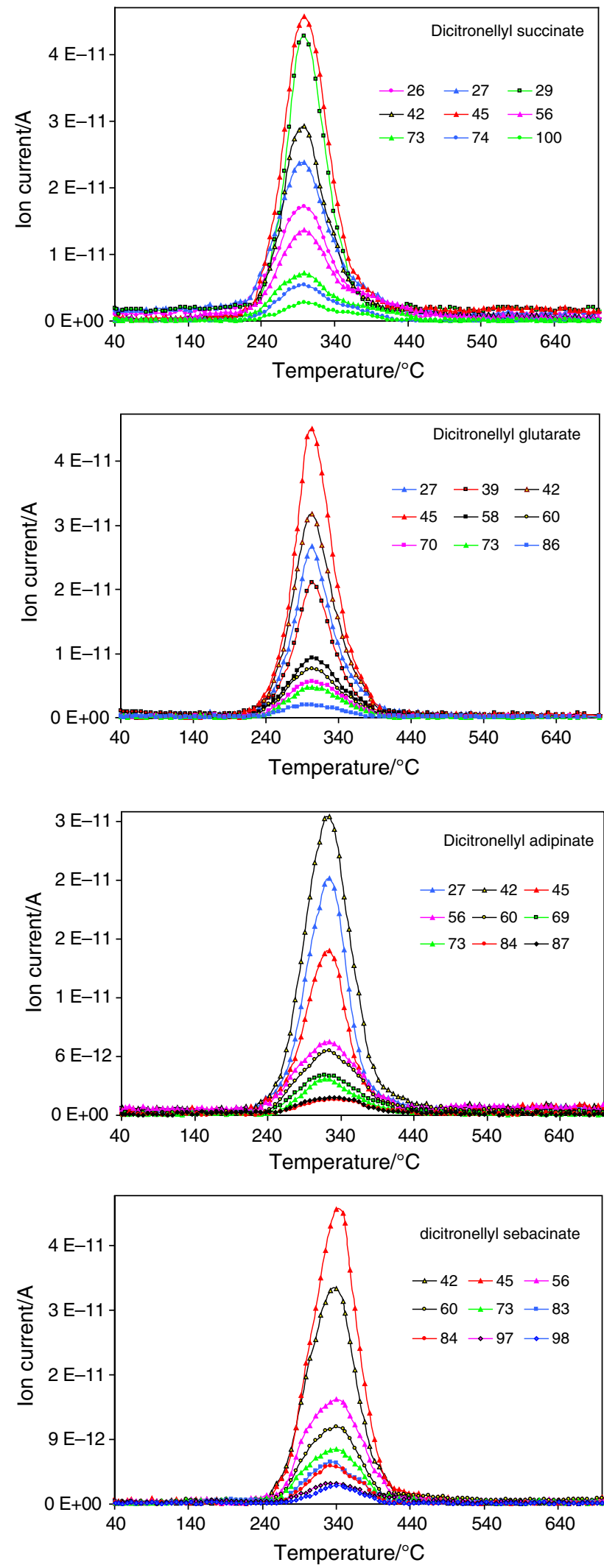

Fig. 8 QMS plots of the characteristic ions $(\mathrm{m} / \mathrm{z})$ formed during decomposition of citronellyl succinate, citronellyl glutarate, citronellyl adipinate, and citronellyl sebacinate in helium of $\mathrm{C}-\mathrm{H}$ bonds at $-\mathrm{CH}_{3},-\mathrm{CH}_{2}-$, and $-\mathrm{O}-\mathrm{CH}_{2}-$ groups (2856-2961 $\mathrm{cm}^{-1}$ ), the deformation vibrations of $\mathrm{C}-\mathrm{H}$ bonds at $-\mathrm{CH}_{3}$ and $-\mathrm{CH}_{2}-$ groups $\left(1353-1456 \mathrm{~cm}^{-1}\right)$, the deformation vibrations of $\mathrm{C}=\mathrm{C}$ double bonds at $=\mathrm{C}-\mathrm{H}$ and $>\mathrm{C}=$ $\mathrm{C}-\mathrm{H}$ groups $\left(780-890 \mathrm{~cm}^{-1}\right)$ and the stretching vibrations of non-conjugated $\mathrm{C}=\mathrm{C}$ double bonds of diesters (low intensity signal at $1672 \mathrm{~cm}^{-1}$ ) $[16,17]$ confirmed their structure.

The ${ }^{1} \mathrm{H}$ NMR and ${ }^{13} \mathrm{C}$ NMR spectra of flavor diesters are placed in Figs. 3 and 4, respectively. The resonance signals at $\delta=5.05-5.15 \mathrm{ppm}$ (e) are characteristic for the protons at carbon-carbon double bonds. The signals at $2.60 \mathrm{ppm}$ (c) for dicitronellyl succinate, at $2.35 \mathrm{ppm}$ (c) and at $1.80 \mathrm{ppm}$ (g) for dicitronellyl glutarate, at $2.30 \mathrm{ppm}(\mathrm{c})$ and $1.62(\mathrm{~g})$ for dicitronellyl adipinate and at 2.26 (c), $1.62 \mathrm{ppm}$ (g) ppm and $1.30 \mathrm{ppm}(\mathrm{h})$ for dicitronellyl sebacinate are the results of the presence of the protons which comes from $-\mathrm{CH}_{2}-$ groups from aliphatic chain of used acidic reagent for their synthesis. In addition, the resonance signals at $\delta=1.96 \mathrm{ppm}$ (b) and in the range 1.15-1.46 ppm $\left(\mathrm{b}^{\prime}, \mathrm{b}^{\prime \prime}\right)$ are from protons in $-\mathrm{CH}_{2}-$ groups of citronellol. The signals at $1.67 \mathrm{ppm}$ (a) and at $0.90 \mathrm{ppm}\left(\mathrm{a}^{\prime}\right)$ indicate on the presence of protons in $-\mathrm{CH}_{3}$ groups from citronellol. At $1.60 \mathrm{ppm}\left(\mathrm{a}^{\prime \prime}\right)$, the protons in $-\mathrm{CH}$ groups are visible. The signals at $\delta=4.10$ (d) directly confirmed the presence of methylene protons $\left(-\mathrm{CH}_{2}-\right)$ characteristic for obtained diesters.

Also, as marked in Fig. 4, all the signals for carbon atoms in the structure of the obtained compounds are present. For all diesters, the resonance signals at $\delta=173 \mathrm{ppm}$ (1) are due to carbons in carbonyl groups $(\mathrm{C}=\mathrm{O})$ of esters. The signals at $125(\mathrm{e})$ and $132\left(\mathrm{e}^{\prime}\right)$ comes from carbons in $\mathrm{C}=\mathrm{C}$. At $64 \mathrm{ppm}$ (d) the carbon signals from $-\mathrm{CH}_{2}-$ groups in surrounding of ester bonds are visible. The signals characteristic for carbons in methyl groups $\left(-\mathrm{CH}_{3}\right)$ at $18,19,25 \mathrm{ppm}\left(\mathrm{a}, \mathrm{a}^{\prime}\right)$, the signals for carbons in methylene groups $\left(-\mathrm{CH}_{2}-\right)$ at 30 (c), at 26,36 , and $37 \mathrm{ppm}\left(\mathrm{b}, \mathrm{b}^{\prime}, \mathrm{b}^{\prime \prime}\right)$, at 20,34 ppm (g) and at $31(\mathrm{~h})$ in dependence of aliphatic chain length in the structure of diesters is indicated. Also, carbon signals for $-\mathrm{CH}$ groups at $26 \mathrm{ppm}\left(\mathrm{a}^{\prime \prime}\right)[18,19]$ are visible.

Decomposition in inert atmosphere

TG/DTG/DSC results of thermal decomposition process of citronellyl diesters in helium are presented in Fig. 5. In addition the data obtained from TG/DTG/DSC analysis are placed in Table 3.

It is clearly visible that the ester compounds decompose in one main, non-well separated step ranges higher than $200{ }^{\circ} \mathrm{C}$ to almost $450{ }^{\circ} \mathrm{C}$ in inert atmosphere. The $5 \%$ of mass loss $\left(T_{5} \%\right)$, which was related to the initial decomposition temperature increases from $210{ }^{\circ} \mathrm{C}$ for citronellyl succinate to $250{ }^{\circ} \mathrm{C}$ for citronellyl sebacinate. This observation is expected and confirms the increase of thermal 
Scheme 1 The decomposition path of diesters in helium

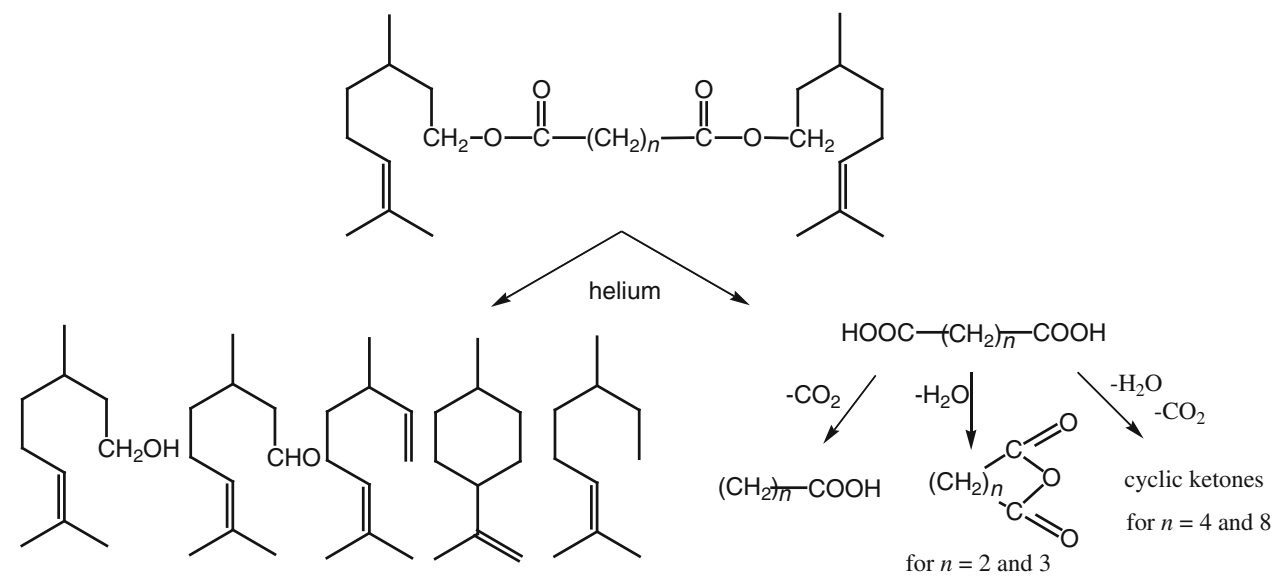

stability of diesters with the increasing of their molecular weight. $T_{\max 1}$ marked from DTG curves are increased from 294 to $336{ }^{\circ} \mathrm{C}$. Also, the DSC analysis performed in the same temperature range and heating rate conditions clearly shows the presence of one endothermic peak at $T_{\max }$ from 290 to $340{ }^{\circ} \mathrm{C}$ which directly corresponds to the mass loss displayed by the TG analysis.

To explain the decomposition path of studied compounds, the analysis of the gaseous products emitted during decomposition was performed by FTIR and QMS. The FTIR spectra of gases evolved during decomposition of diesters gathered at different temperatures in inert atmosphere are presented in Fig. 6.

The results indicate on the formation of various gaseous products during the decomposition process of studied compounds. The FTIR spectra exhibited directly the bands characteristic for carbon dioxide at $2310-2360 \mathrm{~cm}^{-1}$ [20-23], carbon oxide at 2110-2184 $\mathrm{cm}^{-1}$ [22, 23], and water vapor at $3600-3740 \mathrm{~cm}^{-1}$ [22-26]. The presence of the deformation vibrations and the stretching vibrations at 1373-1384, 1448-1458, and 2734-2969 $\mathrm{cm}^{-1}$ related to the $\mathrm{C}-\mathrm{H}$ vibrations in the $-\mathrm{CH}_{3}$ and $-\mathrm{CH}_{2}-$ groups are observed. In addition, the small absorption band at $3081 \mathrm{~cm}^{-1}$ which corresponds to the stretching vibrations of $=\mathrm{C}-\mathrm{H}$ in $=\mathrm{CH}_{2}$ groups is present. The deformation outof-plane vibrations of $=\mathrm{C}-\mathrm{H}$ groups range from 680 to $970 \mathrm{~cm}^{-1}$ and stretching vibrations of $\mathrm{C}=\mathrm{C}$ groups at $1635-1690 \mathrm{~cm}^{-1}$ are also observed on the spectrum. Additional appearance of the strong width band with a maximum at 1052,905 , and $1210 \mathrm{~cm}^{-1}$ is related to the stretching vibrations of $\mathrm{C}-\mathrm{O}$ groups. In addition, the presence of absorption bands at $1715-1880 \mathrm{~cm}^{-1}$ is the result of the stretching vibrations of $\mathrm{C}=\mathrm{O}$ groups. The TG/FTIR results are in accordance with those obtained from TG/ QMS analysis. QMS spectra of gaseous products emitted during decomposition under inert atmosphere of studied diesters are presented in Figs. 7 and 8. TG/QMS analysis allows more precisely to identify the course of the decomposition and the type of formed gaseous products during pyrolysis of diesters. Figure 7 shows the ions $(\mathrm{m} / \mathrm{z})$ characteristic for hydrocarbons which are formed as primary decomposition products during pyrolysis of all four studied diesters (Scheme 1). The presence of ions $(\mathrm{m} / \mathrm{z})$ characteristic for citronellol $(\mathrm{m} / \mathrm{z}=71,68,41,69$, 43), rhodinal $(m / z=41,69,55,95,67), 3,7$-dimethyl-1,6octadiene $(\mathrm{m} / \mathrm{z}=41,55,69,67,82)$, cyclohexane-1methyl-4-(1-methylethenyl) $(\mathrm{m} / \mathrm{z}=81,95,68,67,55)$, and 2-octene-2,6-dimethyl $(\mathrm{m} / \mathrm{z}=69,70,41,55,57)$ are indicated. Figure 8 shows the characteristic ions $(\mathrm{m} / \mathrm{z})$ for the rest, most characteristic decomposition products which are formed during pyrolysis of all studied diesters. The most characteristic decomposition products of dicitronellyl succinate are succcinic acid $(m / z=55,45,74,27,73)$, its dehydrated form: succinic anhydride $(\mathrm{m} / \mathrm{z}=56,26,27$, $100,42)$ and propionic acid $(m / z=74,45,29,73,27)$ which is obtained during partial decarboxylation process of succinic acid. As decomposition products during pyrolysis of citronellyl glutarate, the formation of glutaric acid $(\mathrm{m} / \mathrm{z}=86,42,45,55,58)$, glutaric anhydride $(\mathrm{m} / \mathrm{z}=42$, $70,27,39)$, and butanoic acid $(\mathrm{m} / \mathrm{z}=60,73,42,27,45)$ is mostly expected. The most probable decomposition products for citronellyl adipinate are adipic acid $(\mathrm{m} / \mathrm{z}=60$, $69,87,73,45)$, cyclopentanone $(\mathrm{m} / \mathrm{z}=55,84,56,27,42)$, and pentanoic acid $(\mathrm{m} / \mathrm{z}=60,73,45,27,42)$. Citronellyl sebacinate decomposes into sebacic acid $(\mathrm{m} / \mathrm{z}=98,60,84$, $97,45)$, cyclononanone $(m / z=98,97,83,84,42)$, and nonanoic acid $(m / z=60,73,41,55,43)$ (Fig. 8). The decomposition path of dicitronellyl diesters in inert atmosphere is presented in Scheme 1.

As it was proved by the use of TG coupled with FTIR and QMS analysis, the type of gaseous products indicated on the disruption of ester and $O$-citronellyl bonds, and the partial decarboxylation and elimination of water from primary formed dicarboxylic acids which caused mainly 

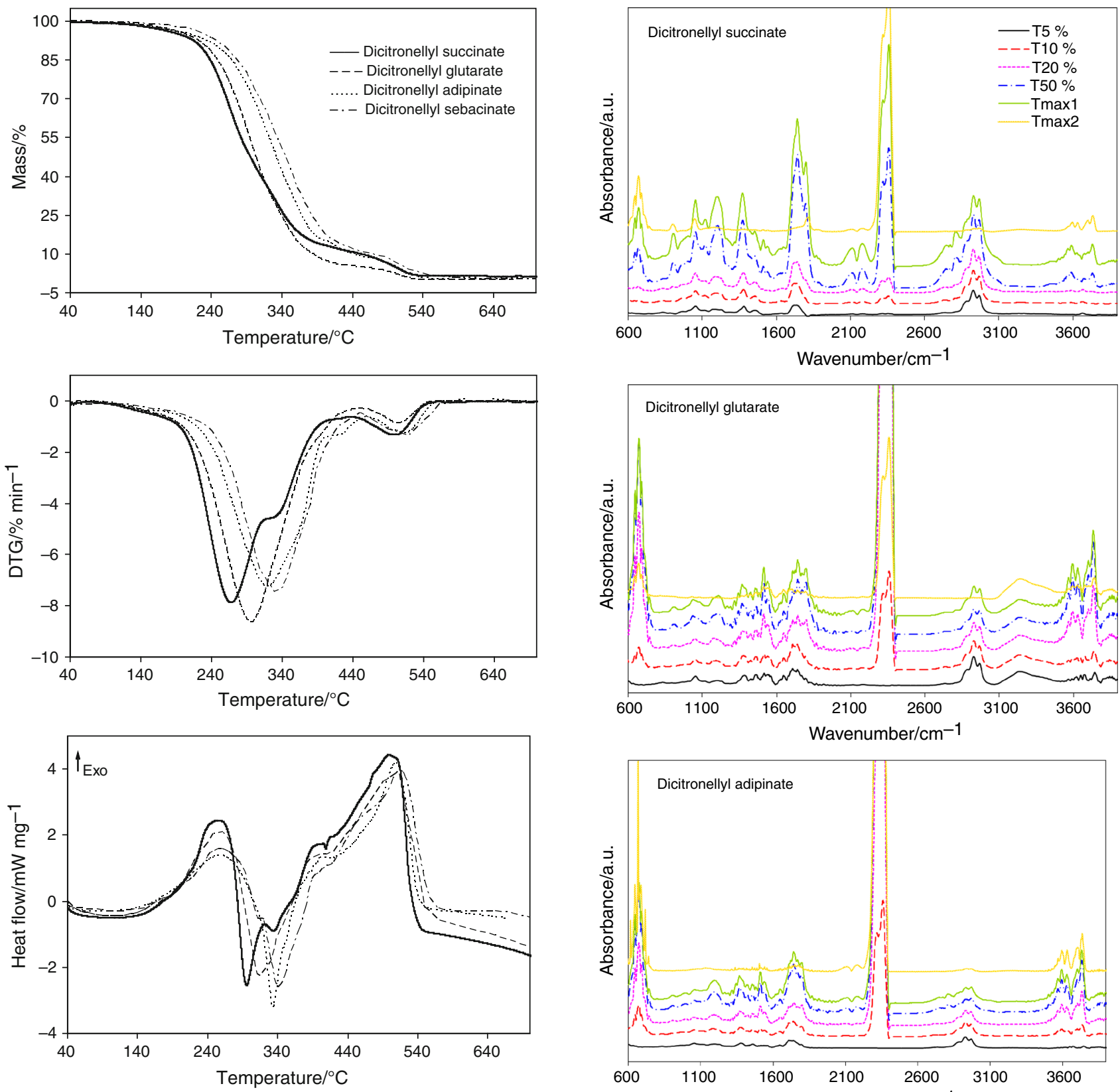

Fig. 9 TG, DTG , and DSC curves of citronellyl diesters in air

Table 4 TG-DTG data of citronellyl diesters in oxidative atmosphere

\begin{tabular}{lcccccc}
\hline Diester & $\begin{array}{l}T_{5} \% / \\
{ }^{\circ} \mathrm{C}\end{array}$ & $\begin{array}{l}T_{10} \% / \\
{ }^{\circ} \mathrm{C}\end{array}$ & $\begin{array}{l}T_{20} \% / \\
{ }^{\circ} \mathrm{C}\end{array}$ & $\begin{array}{l}T_{50} \% \\
{ }^{\circ} \mathrm{C}\end{array}$ & $\begin{array}{l}T_{\max 1} / \\
{ }^{\circ} \mathrm{C}\end{array}$ & $\begin{array}{l}T_{\max 2} / \\
{ }^{\circ} \mathrm{C}\end{array}$ \\
\hline $\begin{array}{c}\text { Dicitronellyl } \\
\text { succinate }\end{array}$ & 200 & 226 & 248 & 292 & $\begin{array}{c}271 / \\
334\end{array}$ & 502 \\
$\begin{array}{c}\text { Dicitronellyl } \\
\text { glutarate }\end{array}$ & 208 & 232 & 259 & 300 & 302 & 507 \\
$\begin{array}{c}\text { Dicitronellyl } \\
\text { adipinate }\end{array}$ & 212 & 250 & 280 & 328 & 333 & 510 \\
$\begin{array}{c}\text { Dicitronellyl } \\
\text { sebacinate }\end{array}$ & 230 & 260 & 290 & 342 & 341 & 515 \\
\hline
\end{tabular}
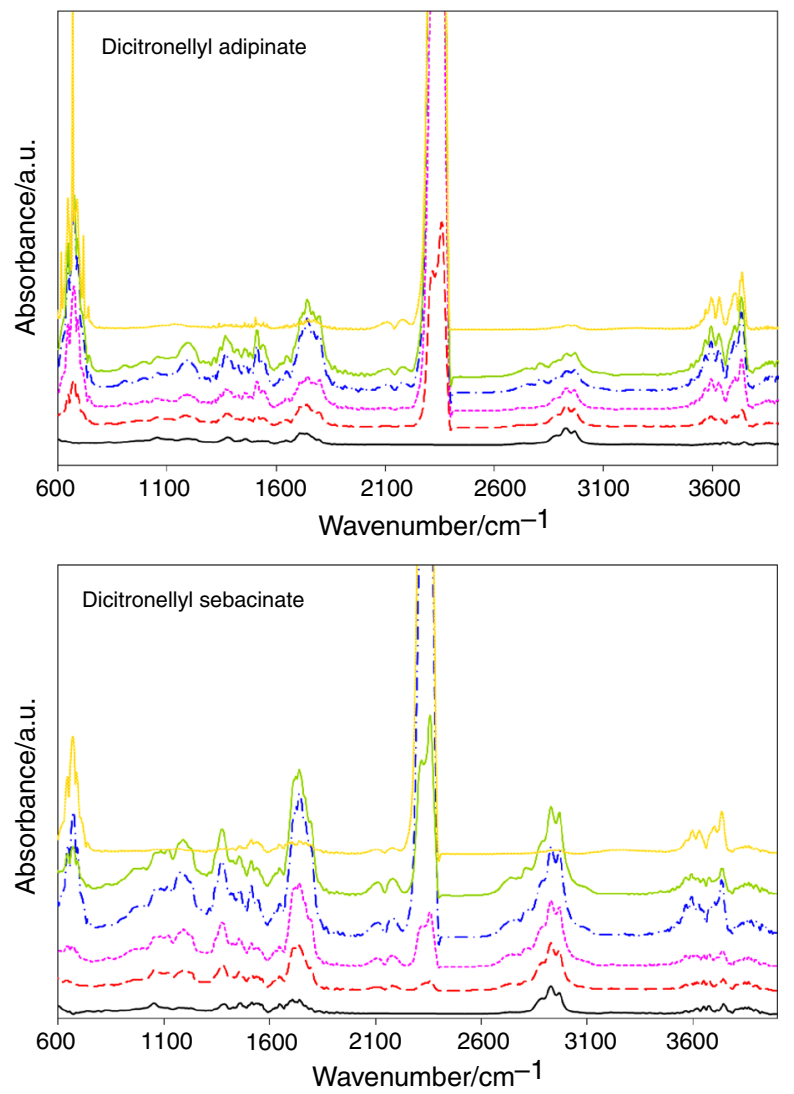

Fig. 10 FTIR spectra of decomposition products emitted in air 


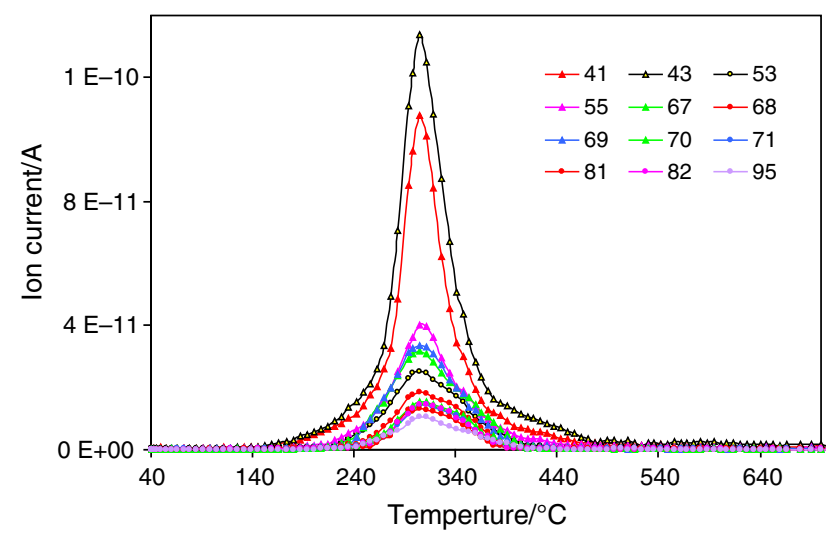

Fig. 11 The example QMS spectra of ions $(\mathrm{m} / \mathrm{z})$ for hydrocarbons which are formed during heating of diesters in air

Table 5 DSC data of citronellyl diesters in oxidative atmosphere

\begin{tabular}{llll}
\hline Diester & $\begin{array}{l}T_{\text {peak } 1} /{ }^{\circ} \mathrm{C} \\
(\mathrm{exo})\end{array}$ & $\begin{array}{l}T_{\text {peak2 }} /{ }^{\circ} \mathrm{C} \\
(\mathrm{endo})\end{array}$ & $\begin{array}{l}T_{\text {peak3 }} /{ }^{\circ} \mathrm{C} \\
(\mathrm{exo})\end{array}$ \\
\hline $\begin{array}{c}\text { Dicitronellyl } \\
\text { succinate }\end{array}$ & 259 & $298 / 338$ & 501 \\
$\begin{array}{c}\text { Dicitronellyl } \\
\text { glutarate }\end{array}$ & 262 & 315 & 520 \\
$\begin{array}{c}\text { Dicitronellyl } \\
\text { adipinate }\end{array}$ & 263 & 335 & 514 \\
$\begin{array}{c}\text { Dicitronellyl } \\
\text { sebacinate }\end{array}$ & 263 & 340 & 517 \\
\hline
\end{tabular}

the formation of monoacids, acid anhydrides, cyclic ketones , and aldehydes fragments.

Decomposition in oxidative atmosphere

TG/DTG/DSC results of thermal decomposition process of citronellyl diesters in air are presented in Fig. 9. The data obtained from TG/DTG/DSC analysis are placed in Tables 4 and 5. Citronellyl diesters are thermally stable up to temperatures $200-230{ }^{\circ} \mathrm{C}$ in dependence of their structure. It is clearly visible that the decomposition process of citronellyl diesters runs in two main steps. The first step was happened to almost $440-450{ }^{\circ} \mathrm{C}$ with $T_{\max 1}$ from 271 to $341{ }^{\circ} \mathrm{C}$. The second was observed above $440-450{ }^{\circ} \mathrm{C}$ with $T_{\max 2}$ above $500{ }^{\circ} \mathrm{C}$. In addition DSC analysis shows the presence of exo- and endothermal signals. The first $\left(T_{\text {peak } 1}\right)$ and third $\left(T_{\text {peak } 3}\right)$ were exothermal. Those signals were directly connected with the oxidation process of diesters $\left(T_{\text {peak } 1}\right)$ and oxidation process of the residue formed after the first decomposition step $\left(T_{\text {peak } 3}\right)$. The second signal $\left(T_{\text {peak2 }}\right)$ was endothermic and it was the
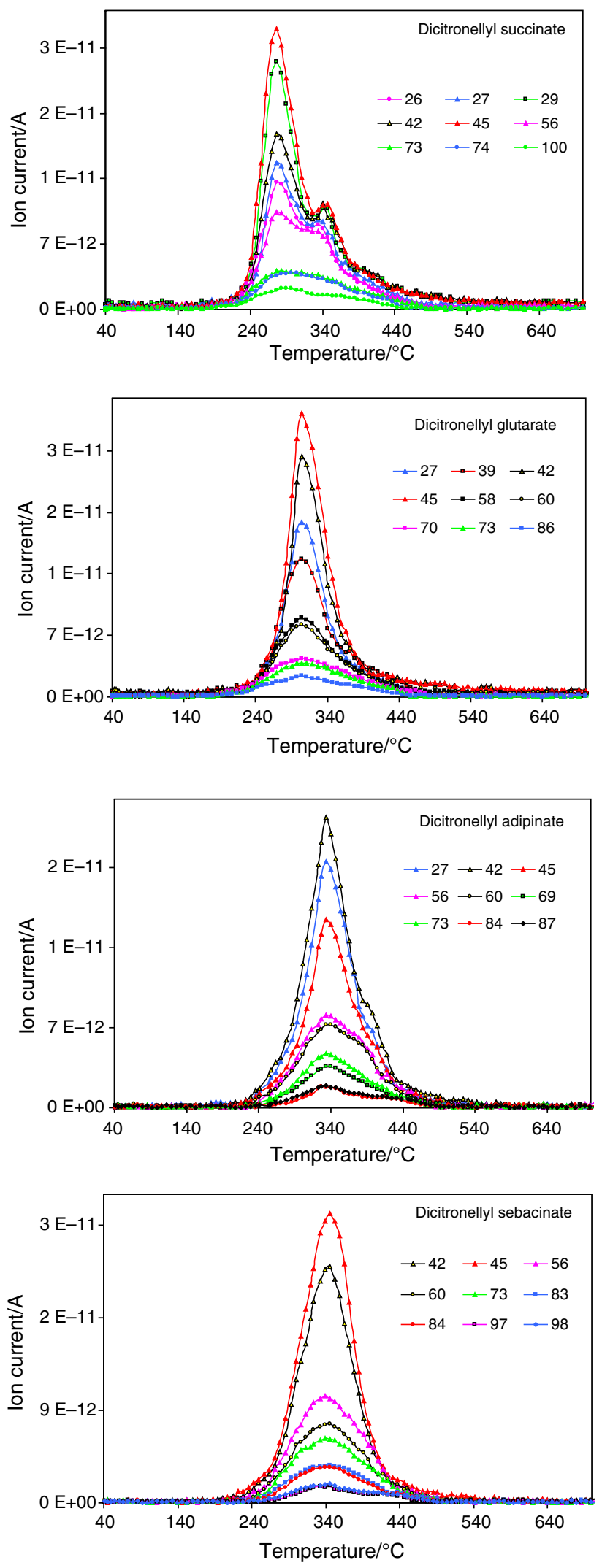

Fig. 12 QMS plots of the characteristic ions $(\mathrm{m} / \mathrm{z})$ formed during decomposition of citronellyl succinate, citronellyl glutarate, citronellyl adipinate, and citronellyl sebacinate in air 
Scheme 2 The decomposition path of diesters in air

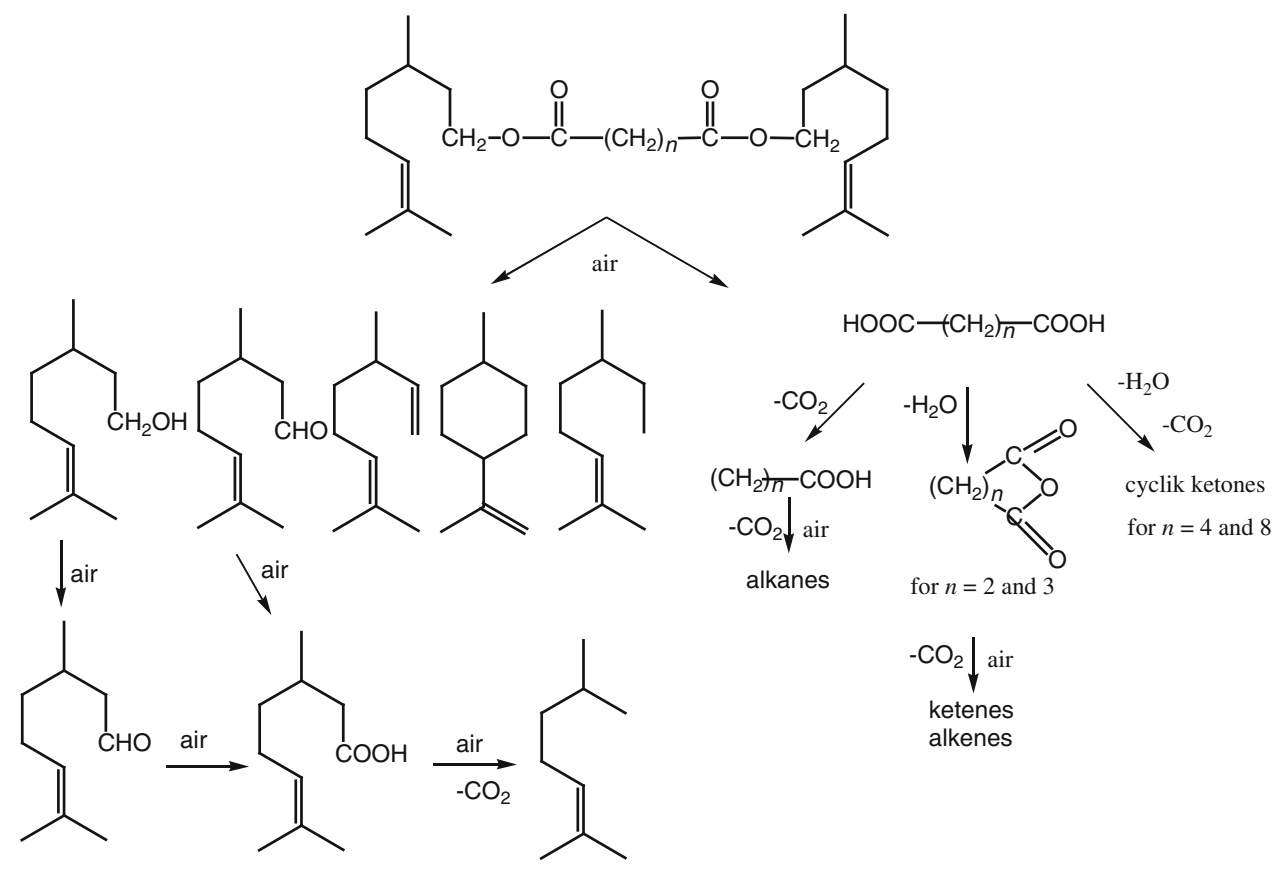

result of the decomposition process of diesters in oxidative atmosphere.

The FTIR spectra of gaseous products emitted during oxidative decomposition of citronellyl diesters gathered at different temperatures are presented in Fig. 10.

At first step of decomposition, the appearance of absorption signals characteristic for carbon dioxide (699 and 2329-2358 $\mathrm{cm}^{-1}$ ), carbon monoxide (2110-2184 $\mathrm{cm}^{-1}$ ) , and water vapor or carboxylic groups (3600-3740 $\mathrm{cm}^{-1}$ ) are observed [20-23, 27, 28]. The signals characteristic for methyl and methylene groups at $1367-1434 \mathrm{~cm}^{-1}$ (deformation vibration of $\mathrm{C}-\mathrm{H}$ ) and at $2870-2980 \mathrm{~cm}^{-1}$ (stretching vibrations of $\mathrm{C}-\mathrm{H})$ and the signals at $830-890 \mathrm{~cm}^{-1}$ (deformation out-of-plane vibrations of $=\mathrm{C}-\mathrm{H}$ groups) indicated on the formation of derivatives of citronellol during the decomposition in air. The signals at $1737-1793 \mathrm{~cm}^{-1}$ (stretching vibrations of $\mathrm{C}=\mathrm{O}$ ) and at $1049-1180 \mathrm{~cm}^{-1}$ (stretching vibrations of $\mathrm{C}-\mathrm{O}$ ) are connected with the formation of acids, acid anhydrides, and aldehydes (the additional signals at $2726-2820 \mathrm{~cm}^{-1}$ ). The results obtained from TG/FTIR analysis were confirmed by the TG/QMS results (Figs. 11, 12). Figure 11 presents the ions $(\mathrm{m} / \mathrm{z})$ characteristic for hydrocarbons which are formed during decomposition of dicitronellyl glutarate in air. The formation of citronellol $(\mathrm{m} / \mathrm{z}=71,68,41,69,43)$, rhodinal $(m / z=41,69,55,95,67)$, 3,7-dimethyl-1,6-octadiene $(m / z=41,55,69,67,82)$, cyclohexane-1-methyl-4-(1methylethenyl) $(\mathrm{m} / \mathrm{z}=81,95,68,67,55)$, and 2-octene-2,6dimethyl $(\mathrm{m} / \mathrm{z}=69,70,41,55,57)$ as primary products are visible. In addition, during oxidation of citronellol and rhodinal in air, the formation of citronellic acid $(\mathrm{m} / \mathrm{z}=69,41$,
$55,95,70)$ and its decarboxylated form: 2-heptene-2,6dimethyl $(\mathrm{m} / \mathrm{z}=41,55,70,43$,$) is expected. Figure 12$ shows the ions characteristic for other products which are formed for all studied diesters in air. Regarding the TG/FTIR/QMS data and the structure of diesters, the primary products are dicarboxylic acids, acid anhydrides, monocarboxylic acids, and cyclic ketones. Decomposition of citronellyl succinate in air gives succcinic acid $(\mathrm{m} / \mathrm{z}=55,45,74$, $27,73)$, succinic anhydride $(\mathrm{m} / \mathrm{z}=56,26,27,100,42)$, and propionic acid $(\mathrm{m} / \mathrm{z}=74,45,29,73,27)$. The formation of glutaric acid $(\mathrm{m} / \mathrm{z}=86,42,45,55,58)$, glutaric anhydride $(\mathrm{m} / \mathrm{z}=42,70,27,39)$, and butanoic acid $(\mathrm{m} / \mathrm{z}=60,73,42$, $27,45)$ during decomposition of citronellyl glutarate is visible. Citronellyl adipinate decomposes into adipic acid $(\mathrm{m} /$ $z=60,69,87,73,45)$, cyclopentanone $(\mathrm{m} / \mathrm{z}=55,84,56$, $27,42)$, and pentanoic acid $(\mathrm{m} / \mathrm{z}=60,73,45,27,42)$. The primary decomposition products of citronellyl sebacinate are sebacic acid $(\mathrm{m} / \mathrm{z}=98,60,84,97,45)$, cyclononanone $(\mathrm{m} / \mathrm{z}=98,97,83,84,42)$, and nonanoic acid $(\mathrm{m} / \mathrm{z}=60,73$, $41,55,43)$. In addition, also the secondary decomposition products e.g., alkanes which are formed during decarboxylation of monoacids and ketenes or alkenes which are obtained during decarboxylation and oxidation of acid anhydrides are expected. The decomposition path of diesters in air is presented in Scheme 2.

However, at $T_{\max 2}$ generally as the decomposition products carbon dioxide and water are observed. The results indicated on the esters and $O$-citronellyl bonds cleavage, partial oxygenation in gaseous phase [29] and decarboxylation process of primary formed decomposition products in air. 


\section{Conclusions}

Thermal stability of citronellyl diesters was higher in inert than in oxidative atmosphere. The $T_{5} \%$ of mass loss was from 210 to $250{ }^{\circ} \mathrm{C}$ in inert atmosphere. However, the $T_{5} \%$ was from 200 to $230{ }^{\circ} \mathrm{C}$ in air atmosphere. The thermal stability of diesters was directly depended on their structure. As the aliphatic chain length increased, the thermal stability also increased.

The citronellyl diesters decomposed in one main step in inert but in two steps in oxidative atmosphere. The formation of mainly monoterpene hydrocarbons, acid anhydrides, monoacids, cyclic ketones, aldehyde fragments, carbon dioxide, and water during pyrolysis was indicated. The emission of monoterpene hydrocarbons, monoacids, cyclic ketones, aldehydes, carbon dioxide, carbon monoxide ,and water as primary products at first decomposition step in air was observed. At second decomposition step mainly the emission of carbon dioxide and water was indicated.

The results presented in this paper directly confirmed the same mechanism of decomposition of studied citronellyl diesters as for previously described geranyl and neryl diesters in inert and oxidative atmospheres.

Open Access This article is distributed under the terms of the Creative Commons Attribution License which permits any use, distribution, and reproduction in any medium, provided the original author(s) and the source are credited.

\section{References}

1. Taylor WG, Schreck CE. Chiral-phase capillary gas chromatography and mosquito repellent activity of some oxazolidine derivatives of (+)- and (-)-citronellol. J Pharm Sci. 1985;74:534-9.

2. Songkro S, Hayook N, Jaisawang J, Maneenuan D, Chuchome T, Kaewnopparat N. Investigation of inclusion complexes of citronella oil, citronellal and citronellol with $\beta$-cyclodextrin for mosquito repellent. J Incl Phenom Macrocycl Chem. 2012;72:339-55.

3. Burdock GA. Fenaroli's handbook of flavor ingredients. Cleveland: CRC Press; 2005.

4. Bauer K, Garbe D, Surburg H. Common fragrance and flavor materials: preparation, properties and uses. New York: Wiley; 2001.

5. Habulin M, Šabeder S, Paljevac M, Primožič M, Knez Ž. Lipasecatalyzed esterification of citronellol with lauric acid in supercritical carbon dioxide/co-solvent media. J Supercrit Fluids. 2007;43:199-203.

6. Macedo GA, Lozano MMS, Pastore GM. Enzymatic synthesis of short chain citronellyl esters by a new lipase from Rhizopus sp. Electron J Biotechnol. 2003;6:72-5.

7. Serri NA, Kamaruddin AH, Long WS. Studies of reaction parameters on synthesis of citronellyl laurate ester via immobilized Candida rugosa lipase in organic media. Bioprocess Biosyst Eng. 2006;29:253-60.
8. Lozano P, Piamtongkam R, Kohns K, De Diego T, Vaultier M, Iborra JL. Ionic liquids improve citronellyl ester synthesis catalyzed by immobilized Candida antarctica lipase B in solvent-free media. Green Chem. 2007;9:780-4.

9. United State Patent, PTC/US1995/008965 Manufacture of perfumes for laundry and cleaning. 1996.

10. United State Patent, 5652205 Perfumes for laundry and cleaning compositions. 1997.

11. Gildemeister E, Hoffmann FR. The volatile oils. New York: Wiley; 1913.

12. Croteau R. Fragrance and flavor substances. Pattensen: D\&PS Verlag; 1980.

13. Worzakowska M, Ścigalski P. TG/DSC/FTIR characterization of linear geranyl diesters. J Therm Anal Calorim. 2013;113:56-60.

14. Worzakowska M, Scigalski P. Synthesis and thermal behavior of linear neryl diesters in inert and oxidative atmosphere. J Therm Anal Calorim. 2014;115:783-92.

15. Patil D, Das D, Nag A. Enzymatic synthesis and analytical monitoring of terpene ester by ${ }^{1} \mathrm{H}$ NMR spectroscopy. Chem Pap. 2011;65:9-15.

16. Sokrates G. Infrared and Raman characteristic group frequencies, tables and charts. New York: Wiley; 2001.

17. NIST chemistry webbook standard reference database number 69 , 2011. http://webbook.nist.gov/chemistry. Accessed 22 Nov 2013.

18. Günther H. NMR spectroscopy: basic principles, concepts, and applications in chemistry. 2nd ed. New York: Wiley; 1995.

19. McLafferty FW. Wiley registry of mass spectra data. 6th ed. New York: Wiley; 1994.

20. Ionashiro EY, Caires FJ, Siqueira ABS, Lima LS, Carvalho CT. Thermal behaviour of fumaric acid, sodium fumarate and its compounds with light trivalent lanthanides. J Therm Anal Calorim. 2012;108:1183-8.

21. Shi J, Wang Z, Liu Y, Wang C. Investigation of thermal behavior of enoxacin and its hydrochloride. J Therm Anal Calorim. 2012;108:299-306.

22. Zhang Q, Saleh ASM, Chen J, Sun P, Shen Q. Monitoring of thermal behavior and decomposition products of soybean oil. J Therm Anal Calorim. 2013. doi: 10.1007/s10973-013-3283-0.

23. Cheng H, Liu Q, Liu J, Sun B, Kang Y, Frost RL. TG-MS-FTIR (evolved gas analysis) of kaolinite-urea intercalation complex. J Therm Anal Calorim. 2013. doi:10.1007/s10973-013-3383-x.

24. Grochowicz M, Gawdzik B, Jaćkowska M, Buszewski B. Thermal characterization of polymeric anion exchangers with a dendrimeric structure. J Therm Anal Calorim. 2013;114:955-61.

25. Parra DF, Forster PL, Łyszczek R, Ostasz A, Lugao AB, Rzączyńska $\mathrm{Z}$. Thermal behavior of the highly luminescent poly(3hydroxybutyrate):Eu(tta) ${ }_{3}\left(\mathrm{H}_{2} \mathrm{O}\right)_{2}$ red-emissive complex. J Therm Anal Calorim. 2013;114:1049-56.

26. Natkański P, Kuśtrowski P, Białas A, Surman J. Effect of $\mathrm{Fe}^{3+}$ ions present in the structure of poly(acrylic acid)/montmorillonite composites on their thermal decomposition. J Therm Anal Calorim. 2013;113:335-42.

27. Mocanu AM, Odochial L, Apostolescu N, Moldoveanu C. Comparative study on thermal degradation of some new diazoamino derivatives under air and nitrogen atmosphere. J Therm Anal Calorim. 2011;103:283-91.

28. Cai GM, Yu WD. Study on the thermal degradation of high performance fibres by TG/FTIR and Py-GC/MS. J Therm Anal Calorim. 2011;104:1183-8.

29. Zapata B, Balmaseda J, Fregoso-Israel E, Torres-García E. Thermo-kinetics study of orange peel in air. J Therm Anal Calorim. 2009;98:309-15. 